\title{
Total Edentulism and Its Epidemiological Surveillance in Oaxaca, Mexico from 2009-2019
}

\author{
Enrique Martínez-Martínez ${ }^{1}$, Carlo Medina-Solís ${ }^{1}$ (D) and Juan Alpuche ${ }^{1,2, *(\mathbb{D})}$ \\ 1 Coordinación General de Posgrado, Facultad de Odontología, Universidad Autónoma Benito Juárez de \\ Oaxaca, Oaxaca de Juárez 68130, Mexico; quique1263@hotmail.com (E.M.-M.); \\ cemedinas@yahoo.com (C.M.-S.) \\ 2 Centro de Investigación Facultad de Medicina UNAM-UABJO, Facultad de Medicina y Cirugía, Universidad \\ Autónoma Benito Juárez de Oaxaca, Oaxaca de Juárez 68130, Mexico \\ * Correspondence: jalpuche.fmc@uabjo.mx
}

Citation: Martínez-Martínez, E.; Medina-Solís, C.; Alpuche, J. Total Edentulism and Its Epidemiological Surveillance in Oaxaca, Mexico from 2009-2019. Oral 2021, 1, 350-356. https://doi.org/10.3390/oral1040035

Academic Editor: Miguel de Araujo Nobre

Received: 10 November 2021 Accepted: 14 December 2021 Published: 16 December 2021

Publisher's Note: MDPI stays neutral with regard to jurisdictional claims in published maps and institutional affiliations.

Copyright: (c) 2021 by the authors. Licensee MDPI, Basel, Switzerland. This article is an open access article distributed under the terms and conditions of the Creative Commons Attribution (CC BY) license (https:/ / creativecommons.org/licenses/by/ $4.0 /)$.

\begin{abstract}
Total edentulism is the loss of all teeth for any cause by a multifactorial process that involves biological and patient-related factors. Studies on edentulism and risk factors in Mexico are limited, and the epidemiological surveillance data is scarce and controversial since official governmental reports are not statistically representative of the country. We estimate the distribution for edentulism according to sociodemographic and socioeconomic variables in adults from a low-income state in 2003 and its progress in Mexico. We analyzed data from the National Performance Evaluation Survey in Oaxaca, Mexico, and the annual reports of the Epidemiological Surveillance System of Oral Pathologies in 2009-2019 using $X^{2}$. Oaxacan patients older than 75 y.o. (17.9\%, $\left.p<0.05\right)$, those with lower schooling $(11.2 \%)$, and diabetes (14.5\%) presented the highest percentage of edentulism. We do not observe differences in edentulism between sex or residence $(p>0.05)$. From 2009 to 2019, country data reports the lowest rate of edentulism in adults over 20 y.o. $(0.32 \%$; $95 \%$ CI $0.18-0.48 \%)$ and the most affected population over 79 y.o. (7.29\%; 95\% CI 5.2-9.30\%). As it is a cumulative phenomenon, it is necessary to establish better surveillance, prevention, and treatment programs to improve the oral health of older thus reducing edentulism.
\end{abstract}

Keywords: edentolous; elderly; oral health

\section{Introduction}

The Global Burden of Diseases, Injuries, and Risk Factors Study GBD reports oral diseases as the most significant prevalence disorder globally in 2018 [1]. Oral diseases affected almost 3.49 billion people worldwide in 2019 [2]; dental caries and periodontal diseases represent the most significant oral health problems. Dental caries are the leading cause of tooth loss in children and young people, while periodontal diseases are in adults. Severe periodontal disease can cause tooth loss in approximately $10 \%$ of the world's population [3]. Although in the world, epidemiological data related to oral health have been directed mainly to the study of these two diseases, both have cumulative chronic character, which leads to tooth loss if they are not treated early to prevent complications.

Total edentulism is the loss of all teeth for any cause through a multifactorial process that involves biological factors and factors related to the patient [4]. Healthy teeth will be maintained with good oral hygiene, avoiding the accumulation of dental plaque, the leading etiological agent of tooth decay and periodontal disease. Unfortunately, dental health in low-income regions is not a priority, and they do not attend constant check-ups or follow up on their treatment.

One of the most critical consequences of edentulism is the nutritional status of the people who suffer from it [5]. Toothless older people modify their diet, avoiding foods that are difficult to chew, such as fruits and vegetables (foods associated with the prevention of chronic diseases), affecting their nutritional status [6]. In addition, some reports associated 
edentulism with chronic diseases, such as cancer of the digestive tract and cardiovascular diseases [7].

There are only a few studies carried out in Mexico on edentulism and risk factors [8,9]. For example, Islas-Granillo et al., (2011) studied asylees aged 60 years and over in Pachuca, Hidalgo, to report the prevalence and risk indicators for edentulism; they concluded that variables of diverse nature affected edentulism, with a significant association between smoking and having received radiotherapy [8]. However, official information on the epidemiological surveillance of total edentulism in Mexico is scarce and even more controversial since official reports from Mexican health authorities are not statistically representative of the country.

Oaxaca is the second-lowest income state of Mexico, with 4.13 million inhabitants in 2020, mostly living in rural areas, with no public epidemiological data for oral diseases available. Therefore, the objective of this study was to estimate the distribution of total edentulism according to sociodemographic and socioeconomic variables in adults aged 18 years and over from Oaxaca, Mexico, in the years 2002-2003 and to compare it with the progress reported in the epidemiological surveillance system of oral health in Mexico from 2009 to 2019.

\section{Materials and Methods}

\subsection{Data Collection from the Oaxacan Population}

The data for a low-income state (Oaxaca, México) was provided by the National Performance Evaluation Survey (NPES) 2002-2003, part of the technical collaboration between the Ministry of Health of Mexico and the World Health Organization Global Survey project of health. Part of the methodology was published for other states of the country $[9,10]$. The National Performance Evaluation Survey (NPES) is a cross-sectional, national study in the Oaxacan adult population $\geq 18$ years of age. The sample design was probabilistic, multi-stage, stratified, and conglomerates, with a $5 \%$ maximum relative error, $95 \%$ confidence, non-response rate of $15 \%$, and a design effect of 1.7 . Three strata were considered: (a) city or metropolitan area ( $>100,000$ inhabitants); (b) urban complement (localities with 2500 to 99,999 inhabitants), and (c) rural area (localities with less than 2500 inhabitants). With these criteria, the sample size for Oaxaca, México was 1238 households.

The NPES variables collected were: Edentulism, defined by total loss of teeth for any causes; Age, grouped by range (18-24, 25-34, 35-44, 45-54, >64 years old); Schooling, defined as the total number of school years completed, ranged ( $<6$ years, or primary school; 6 to 8 years, or secondary school; 9 to 11 years, or preparatory school, 12 to 15 years, or superior education, and $>16$ years or postgraduate studies); Diabetes, as dichotomic presence in individuals; and Place of residence, defined by the type of residence area as rural, or less than 2500 inhabitants, urban for 2500 to 99,999 inhabitants, and Metropolitan for more than 100,000 inhabitants.

\subsection{Data Collection for Mexico from 2009-2019}

The progress in edentulism was measured using data from the annual reports (2009-2019) of the Epidemiological Surveillance System for Oral Pathologies (SIVEPAB) of the General Bureau of Epidemiology of the Ministry of Health, in charge of collecting information on patients who attend at least 355 sentinel epidemiological surveillance units in the 32 states of México, it is non-probabilistic, for convenience sampling. Therefore, the information collected is not representative and may overestimate the prevalence of oral diseases, minimizing edentulism prevalence in the Mexican population.

\subsection{Statistical Analysis}

The NPES data analysis included the self-report of edentulism as a dependent variable, understanding as a case the people who reported not having any natural teeth in their mouths. The independent variables for this analysis were age, sex, place of residence, education, and diabetes. Due to the design used in the survey sampling, to perform 
the statistical analysis, we use the SVY module (for complex samples) of the STATA 9.0 statistical package. All the variables were qualitative, so the summary measures are frequencies and percentages in the descriptive analysis. We performed bivariate analysis to find the differences in the distribution of the rates of edentulism through the different independent variables included, using X2 tests. A $p$-value less than 0.05 was considered statistically significant.

\subsection{Ethical Approval}

This study was approved by the Ethic in Research Committee of the Dentistry Faculty of Universidad Autonoma Benito Juarez de Oaxaca, Mexico (CEI01020150804), according to art. 17, fracc I of the Reglamento de la Ley General de Salud en Materia de Investigación para la Salud.

\section{Results}

\subsection{Oaxacan Population Analysis from National Performance Evaluation Survey \\ 3.1.1. Edentulism by Age}

Data analysis from Oaxaca of the National Performance Evaluation Survey found that the average age for the non-edentulous subjects was 38.45 years old ( $95 \%$ CI $37.55-39.35$ ), and for the edentulous, 54.66 years old (95\% CI 49.69-59.63). Minaya-Sánchez et al., 2010, reported that older people have the highest percentage of subjects with total tooth loss [11]. Our data shows the highest rate of edentulism $(17.9 \%)$ was presented by those who were 65 years old and older $(p<0.05)$. Regarding the prevalence of edentulism, we estimated a rate of $4.7 \%$, equivalent to 151,507 Oaxacan population aged 18 and over with a complete absence of natural teeth-Table 1 .

Table 1. Prevalence of edentulism by age in Oaxaca, México according to NPES.

\begin{tabular}{cccc}
\hline Age & Non-Edentulous ${ }^{\mathbf{1}}$ & Edentolous & $p$-Value \\
\hline $18-25$ & $555,599(98.9 \%)$ & $6460(2.2 \%)$ & 0.0001 \\
$25-34$ & $869,556(98.8 \%)$ & $10,712(1.2 \%)$ & 0.0001 \\
$35-44$ & $706.086(95.5 \%)$ & $33,337(4.5 \%)$ & 0.0001 \\
$45-54$ & $446,701(95.4 \%)$ & $21,609(4.6 \%)$ & 0.0001 \\
$55-64$ & $233,201(88.7 \%)$ & $29,787(11.3 \%)$ & 0.0001 \\
$>64$ & $227,505(82.1 \%)$ & $49,602(17.9 \%)$ & 0.0001 \\
Total & $2,038,648(95.3 \%)$ & $151,507(4.7 \%)$ & \\
\hline
\end{tabular}

${ }^{1}$ Weighted population.

\subsubsection{Edentulism by Schooling}

Analysis of schooling shows that the prevalence of edentulism decreased with higher educational attainment, which indicates inequalities in oral health. Most of the population completed primary school (58.1\%), which, added to the percentage of those who had less than primary school, reached almost $75 \%$. On the other hand, subjects with the lowest schooling rate constituted those with university studies or more. Some authors also reported in Mexico the same data using various health and socioeconomic position [12]. Table 2.

\subsubsection{Edentulism on Diabetes Patients}

On the other hand, patients with chronic diseases, such as diabetes, have worse oral health states than their counterparts without these diseases (Hugo et al., 2007). We found that people with diabetes present the highest prevalence of edentulism. Diabetic patients have the highest percentage of edentulism $(14.5 \%)$ compared to non-diabetics $(5.7 \%)$; these differences were statistically significant $(p<0.05)$-Table 2 . 


\subsubsection{Edentulism by Residence Area}

The population living in rural areas had the highest percentage of edentulous people $(5.8 \%)$ compared to people residing in urban $(4.6 \%)$ and metropolitan regions $(1.9 \%)$. Although this was higher among rural residents, this difference was not statistically significant $(p>0.05)$-Table 2 .

Table 2. Prevalence of edentulism by schooling, diabetes presence, and residence area in Oaxaca, México according to NPES analysis.

\begin{tabular}{ccccc}
\hline & & Non-Edentulous & Edentolous $^{1}$ & $p$-Value \\
\hline Schooling & $<6$ years & $460,695(88.8 \%)$ & $58,109(11.12 \%)$ & \\
& 6-8 years & $1,788,738(96.4 \%)$ & $66,456(3.6 \%)$ & \\
& $9-11$ years & $434,686(96.5 \%)$ & $15,640(3.5 \%)$ & \\
& $12-15$ years & $225,217(98 \%)$ & $4576(2 \%)$ & \multirow{2}{*}{0.0015} \\
& $\geq 16$ years & $129,312(95.1 \%)$ & $6726(4.9 \%)$ & \\
Diabetes & Diabetic & $2,900,037(95.8 \%)$ & $128,018(4.2 \%)$ & \multirow{2}{*}{0.0248} \\
& Non-diabetic & $138,611(85.5 \%)$ & $23,489(14.5 \%)$ & \\
\hline \multirow{2}{*}{ Residence } & Rural & $1,215,463(94.2 \%)$ & $75,473(5.8 \%)$ & \\
& Urban & $1,395,892(95.4 \%)$ & $67,580(4.6 \%)$ & 0.103 \\
\hline
\end{tabular}

${ }^{1}$ Weighted population.

\subsection{Edentulism in México from SISVEPAB}

According to the Oral Pathologies Epidemiological Surveillance System (SISVEPAB), in the 2009-2019 period in Mexico, edentulism in adults over 20 years old was $0.32 \%$ (95\% CI $0.18-0.48 \%)$, with statistically significant differences $(p>0.05)$ between age groups. Data show edentulism increases with age groups (Figure 1).

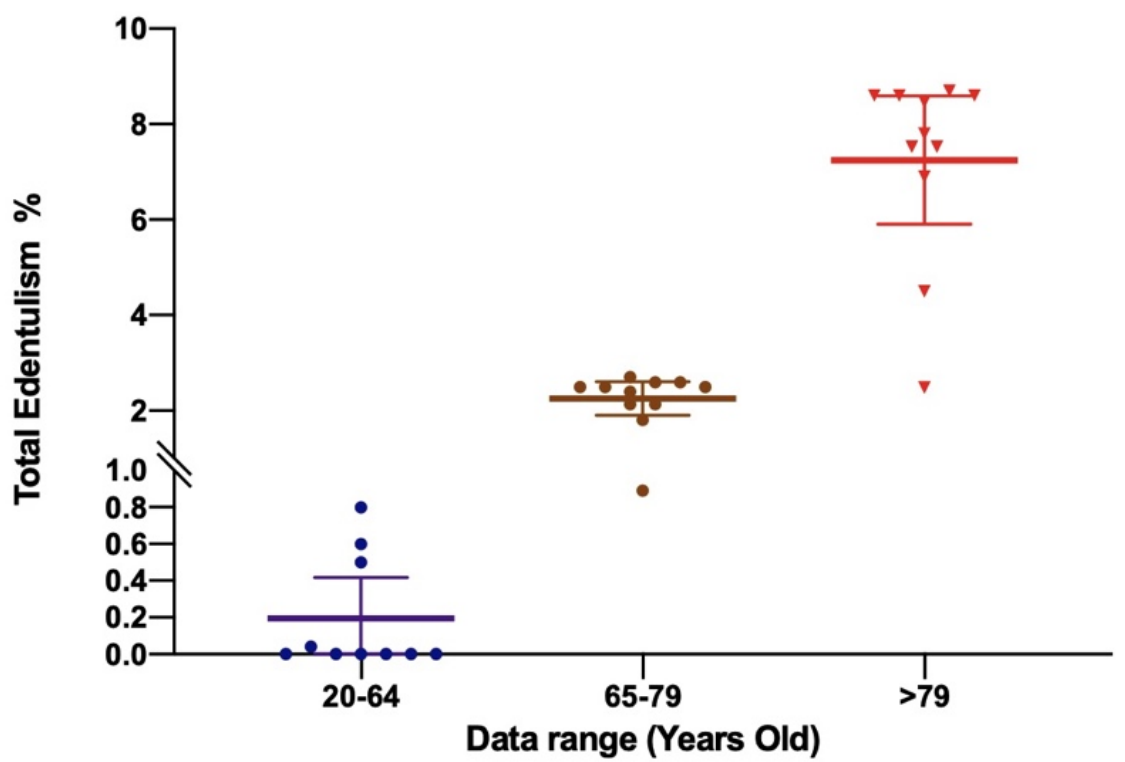

Figure 1. Total edentulism (\%) among age groups $20-64,65-79$, and over 79 years old. (Mean $\pm 95 \% \mathrm{CI}$ ).

In the country, edentulous people between 65 and 79 years old was $2.52 \%$, with the year 2018 being the lowest reported rate ( $0.8 \%)$; Regarding the population over 79 years old, the average edentulism was $7.25 \%$, the highest data reported for this surveillance system. In 2018, the lowest rate was $2.48 \%$, while the highest was the year 2019 with the year $8.6 \%$ (Table 3). 
Table 3. Total edentulism in Mexico from 2009 to 2019 by age groups, according to SISVEPAB from the General Bureau of Epidemiology of the Ministry of Health.

\begin{tabular}{ccccccc}
\hline \multicolumn{7}{c}{ Age Groups (Years Old) } \\
Year & $\mathbf{2 0 - 6 4} \mathbf{( \% )}$ & $\mathbf{6 5 - 7 9 ( \% )}$ & $\mathbf{7 7 9} \mathbf{( \% )}$ & Mean & C.I. 95\% Min & C.I. 95\% Max \\
\hline 2009 & $>1$ & 2.6 & 4.5 & 2.1 & 0.2069 & 9.057 \\
2010 & 0 & 2.14 & 7.53 & 2.468 & 0.0037 & 45.900 \\
2011 & 0 & 2.14 & 7.53 & 2.468 & 0.0037 & 45.900 \\
2012 & 0 & 1.81 & 8.47 & 2.67 & 0.0045 & 51.750 \\
2013 & 0 & 2.5 & 8.6 & 2.875 & 0.0045 & 61.670 \\
2014 & 0 & 2.5 & 8.6 & 3.025 & 0.0056 & 78.390 \\
2015 & 0 & 2.4 & 6.9 & 2.575 & 0.0059 & 65.940 \\
2016 & 0.6 & 2.6 & 8.7 & 3.225 & 0.2951 & 12.480 \\
2017 & 0.5 & 2.5 & 7.8 & 2.825 & 0.1760 & 12.550 \\
2018 & 0.04 & 0.89 & 2.48 & 0.8775 & 0.0148 & 6.372 \\
2019 & 0.8 & 2.7 & 8.6 & 3.15 & 0.2282 & 13.350 \\
\hline
\end{tabular}

\section{Discussion}

The only available data for edentulism in a low-income state in Mexico was from the NPES for Oaxaca in 2002-2003, showing that total tooth loss in adults aged 18 years and over has a diverse range depending on sociodemographic and socioeconomic variables.

Regarding age, this study corroborated the observations of several studies [13-17], it was observed that older people present the highest percentage of total tooth loss, dental caries, and periodontal disease are considered chronic of a cumulative nature; when age increases, the possibility that both conditions will worsen (if they are not restricted with adequate treatments or even prevented), the tooth loss increases.

Schooling often is used to determine socioeconomic position [13]; in Oaxaca, the prevalence of edentulism decreased with higher educational attainment, indicating the existence of inequalities in oral health; this data supported other studies carried out in low-income regions using various indicators of both health and socioeconomic position [12,18-21]. In addition, health evidence suggests an association between health and social status: individuals with better socioeconomic status enjoy better health [22-24].

Patients with chronic diseases, such as diabetes, have worse oral health status than their counterparts without these diseases [25-28]. In this study, we found that diabetic patients from Oaxaca presented the highest prevalence of edentulism. Although, from a traditional perspective, the importance of keeping teeth in good functional condition lies in its positive impact on a better quality of life [24] and the fact of the association of edentulism with chronic diseases, in addition, other studies have documented the negative impact of edentulism on people's nutritional status $[29,30]$.

Regarding the epidemiological surveillance of edentulism in Mexico, a lack of planning is evidenced in the SISVEPAB yearly publications, based on the theory that a large part of the Mexican population mainly seeks dental care only when there is pain. As a result, the official reports may overestimate the prevalence of oral diseases in different age groups. Similarly, people who have lost their teeth do not seek dental care as often as those who still have them. For this reason, the study can minimize the prevalence of total tooth loss in the population.

Data from SISVEPAB show that total edentulism of $7.25 \%$ for older people ( $>79$ y.o.) differs from other studies in Mexico. Padilla-Sánchez et al. (2017) report $12 \%$ of total edentulism in a population of older adults in Mexico City [31], while Fernández-Barrera et al. (2016) report 15.7\% for the city of Pachuca, Mexico [32]. Menchaca-Díaz et al. Report 10.6\% for a population in the north of the country [33].

\section{Conclusions}

In Oaxaca, Mexico, the prevalence of total tooth loss was related to sociodemographic variables (age, sex, and residence), showing a trend towards older age a higher percentage of edentulism. Moreover, edentulism depends on education; the higher the level of 
education, the lower the edentulous rate. Likewise, diabetes plays an essential role in the prevalence of edentulism; adults 18 years of age and older who suffer from the pathology have a higher percentage of edentulism than the healthy population.

According to reports by the SIVEPAV, from 2009-2019, the cases of edentulism have not decreased. As it is a cumulative phenomenon, it is necessary to establish cost-effective prevention and treatment programs for oral diseases that seek to improve the oral health of adults and older adults that allow reducing the percentages of edentulism among this population.

\section{Limitation and Strength}

This study has some limitations, and the first limitation is on the age of populations; from Oaxaca (NPES), we have data from 18 years old, and for country data, we have from 20 years old. The second limitation comes from official data collected from SIVEPAB, where between 2009 and 2015, data only had one digit, depreciating with values lower than 1.0 on prevalence. Finally, the third limitation comes from the SIVEPAB data from 2018, where data presented over the lower limits of the table, suggesting an error in official data; however, we could not control those secondary data. Otherwise, this study is the first one regarding edentulism distribution in Oaxaca, Mexico, one of the few studies in the open population in Mexico.

Author Contributions: Conceptualization and methodology, C.M.-S. and E.M.-M.; formal analysis, C.M.-S.; investigation, E.M.-M.; resources, J.A.; data curation, C.M.-S.; writing-original draft preparation, E.M.-M.; writing —review and editing, J.A.; supervision, J.A.; project administration, J.A. All authors have read and agreed to the published version of the manuscript.

Funding: This research received no external funding.

Institutional Review Board Statement: This study was approved by the Ethics in Research Committee of the Dentistry Faculty of Universidad Autonoma Benito Juarez de Oaxaca (CEI01020150804), according to the article. 17, fraction I of the Reglamento de la Ley General de Salud en Materia de Investigación para la Salud. In this study, non-personal or related data was used, SIVEPAB database are public in: https:/ / www.gob.mx/salud/acciones-y-programas/sivepab-sistema-de-vigilanciaepidemiologica-de-patologias-bucales (accessed on 8 November 2021).

Informed Consent Statement: Informed consent was obtained from all subjects involved in the study.

Data Availability Statement: All data used are public in: https://www.gob.mx/salud/accionesy-programas / sivepab-sistema-de-vigilancia-epidemiologica-de-patologias-bucales (accessed on 8 November 2021).

Conflicts of Interest: The authors declare no conflict of interest.

\section{References}

1. GBD 2017 Disease and Injury Incidence and Prevalence Collaborators. Global, regional, and national incidence, prevalence, and years lived with disability for 354 diseases and injuries for 195 countries and territories, 1990-2017: A systematic analysis for the Global Burden of Disease Study 2017. Lancet 2018, 392, 1789-1858. [CrossRef]

2. GBD Compare I IHME Viz Hub. Available online: https://vizhub.healthdata.org/gbd-compare/ (accessed on 30 November 2021).

3. OMS. Salud Bucodental. 2020. Available online: https://www.who.int/es/news-room/fact-sheets/detail/oral-health (accessed on 9 November 2021).

4. Felton, D.A. Edentulism and Comorbid Factors. J. Prosthodont. 2009, 18, 88-96. [CrossRef]

5. Hussein, S.; Kantawalla, R.F.; Dickie, S.; Suarez-Durall, P.; Enciso, R.; Mulligan, R. Association of Oral Health and Mini Nutritional Assessment in Older Adults: A Systematic Review with Meta-analyses. J. Prosthodont. Res. 2021, 20, 207. [CrossRef]

6. Banerjee, R.; Chahande, J.; Banerjee, S.; Radke, U. Evaluation of relationship between nutritional status and oral health related quality of life in complete denture wearers. Indian J. Dent. Res. 2018, 29, 562-567. [CrossRef]

7. Casanova-Rosado, A.; Casanova-Rosado, J.; Minaya-Sánchez, M.; Robles-Minaya, J.; Casanova-Sarmiento, J.; Márquez-Corona, M.; Pontigo-Loyola, A.; Isla-Granillo, H.; Mora-Acosta, M.; Márquez-Rodríguez, S.; et al. Association of Edentulism with Various Chronic Diseases in Mexican Elders 60+ Years: Results of a Population-Based Survey. Healthcare 2021, 9, 404. [CrossRef]

8. Medina-Solís, C.E.; Pérez-Núñez, R.; Maupomé, G.; Avila-Burgos, L.; Pontigo-Loyola, A.P.; Patiño-Marín, N.; Villalobos-Rodelo, J.J. National survey on edentulism and its geographic distribution, among Mexicans 18 years of age and older (with emphasis in WHO age groups). J. Oral Rehabil. 2008, 35, 237-244. [CrossRef] 
9. Medina-Solís, C.E.; Pérez-Núñez, R.; Maupomé, G.; Casanova-Rosado, J.F. Edentulism among Mexican Adults Aged 35 Years and Older and Associated Factors. Am. J. Public Health 2006, 96, 1578-1581. [CrossRef] [PubMed]

10. Islas-Granillo, H.; Borges-Yáñez, S.A.; Lucas-Rincón, S.; Medina-Solís, C.E.; Casanova-Rosado, A.; Márquez-Corona, M.; Maupome, G. Edentulism risk indicators among Mexican elders 60-year-old and older. Arch. Gerontol. Geriatr. 2011, 53, 258-262. [CrossRef]

11. Minaya-Sánchez, M.; Medina-Solís, C.E.; Casanova-Rosado, J.F.; Casanova-Rosado, A.J.; Márquez-Corona MD, L.; Islas-Granillo, H.; Islas-Márquez, A.J. Pérdida de dientes y variables del estado periodontal asociadas en hombres policías adultos. Gac. Médica México 2010, 146, 264-268.

12. Escoffié-Ramírez, M.; Medina-Solís, C.E.; Pontigo-Loyola, A.P.; Acuña-González, G.; Casanova-Rosado, J.F.; Colome-Ruiz, G.E. Asociación de labio y / o paladar hendido con variables de posición socioeconómica: Un estudio de casos y controles. Rev. Bras. Saúde Matern. Infant. 2010, 10, 323-329. [CrossRef]

13. Hugo, F.N.; Hilgert, J.B.; da Luz Rosário de Sousa, M.; da Silva, D.D.; Pucca, G.A. Correlates of partial tooth loss and edentulism in the Brazilian elderly. Community Dent. Oral Epidemiol. 2007, 35, 224-232. [CrossRef]

14. Hugo, F.N.; Hilgert, J.B.; Sousa, M.D.L.R.D.; Cury, J.A. Oral status and its association with general quality of life in older independent-living south-Brazilians. Community Dent. Oral Epidemiol. 2009, 37, 231-240. [CrossRef]

15. Cocco, F.; Guglielmo, C.; Strohmenger, L.; Ardizzone, V.C.; Cagetti, M.G. The burden of tooth loss in Italian elderly population living in nursing homes. BMC Geriatr. 2018, 18, 76. [CrossRef]

16. Pengpid, S.; Peltzer, K. The prevalence of edentulism and their related factors in Indonesia, 2014/15. BMC Oral Health 2018, 18, 118. [CrossRef]

17. Müller, F.; Naharro, M.; Carlsson, G.E. What are the prevalence and incidence of tooth loss in the adult and elderly population in Europe? Clin. Oral Implant. Res. 2007, 18, 2-14. [CrossRef] [PubMed]

18. del Socorro Herrera, M.; Lucas-Rincón, S.E.; Medina-Solís, C.E.; Maupomé, G.; de Lourdes Márquez-Corona, M.; Islas-Granillo, H.; Islas-Márquez, A.J.; Atitlán-Gil, A. Desigualdades socioeconómicas en salud bucal: Factores asociados a la frecuencia de cepillado dental en escolares nicaragüenses. Rev. Investig. Clín. 2009, 61, 489-496.

19. Nagaraj, E.; Manjani, N.; Madalli, P.; Astejar, D. Socioeconomic factors and complete edentulism in north Karnataka population. Journal of Indian Prosthodontic Society. 2014, 14, 24-28. [CrossRef]

20. CES Odontología. CES Odontol. 2021, 25, 22-31. [CrossRef]

21. Ávila-Márquez, K.; Medina-Solís, C.; Ascencio-Villagran, A.; Pontigo-Loyola, A.P.; Casnova-Rosado, J.F.; Gonzalez-Garcia, J. Dientes perdidos en pacientes que acuden a las clínicas de odontología de la UAEH. In Memorias del XXI Congreso Nacional e Internacional de Posgrado e Investigación en Odontología y Reunión Anual de la división Mexicana de la IADR; UNAM: Ciudad de México, Mexico, 2009; p. 176.

22. Ningrum, V.; Bakar, A.; Shieh, T.-M.; Shih, Y.-H. The Oral Health Inequities between Special Needs Children and Normal Children in Asia: A Systematic Review and Meta-Analysis. Healthcare 2021, 9, 410. [CrossRef]

23. Scarpelli, A.C.; Paiva, S.M.; Viegas, C.M.; Carvalho, A.C.; Ferreira, F.M.; Pordeus, I.A. Oral health-related quality of life among Brazilian preschool children. Community Dent. Oral Epidemiol. 2013, 41, 336-344. [CrossRef]

24. Chaffee, B.W.; Rodrigues, P.H.; Kramer, P.F.; Vitolo, M.R.; Feldens, C.A. Oral health-related quality-of-life scores differ by socioeconomic status and caries experience. Community Dent. Oral Epidemiol. 2017, 45, 216-224. [CrossRef] [PubMed]

25. Speight, J.; Reaney, M.D.; Barnard, K.D. Not all roads lead to Rome-a review of quality of life measurement in adults with diabetes. Diabet. Med. 2009, 26, 315-327. [CrossRef]

26. Eljedi, A.; Mikolajczyk, R.T.; Kraemer, A.; Laaser, U. Health-related quality of life in diabetic patients and controls without diabetes in refugee camps in the Gaza strip: A cross-sectional study. BMC Public Health 2006, 6, 268. [CrossRef] [PubMed]

27. Kind, P. Introduction to diabetes special issue of value in health. Value Health 2000, 3, 1-2. [CrossRef] [PubMed]

28. Luscombe, F. Health-Related Quality of Life Measurement in Type 2 Diabetes. Value Health 2000, 3, S15-S28. [CrossRef]

29. Algra, Y.; Haverkort, E.; Kok, W.; van Etten-Jamaludin, F.; van Schoot, L.; Hollaar, V.; Naumann, E.; de van der Schueren, M.; Jerković-Ćosić, K. The Association between Malnutrition and Oral Health in Older People: A Systematic Review. Nutrients 2021, 13, 3584. [CrossRef]

30. Gondivkar, S.M.; Gadbail, A.; Gondivkar, R.S.; Sarode, S.; Sarode, G.; Patil, S.; Awan, K.H. Nutrition and oral health. Disease-AMonth 2019, 65, 147-154. [CrossRef]

31. Padilla-Sánchez, M.D.L.; Saucedo-Campos, G.; Ponce-Rosas, E.R.; González-Pedraza, A.; De México, U.N.A. Estado de dentición y su impacto en la calidad de vida en adultos mayores. CES Odontol. 2017, 30, 16-22. [CrossRef]

32. Fernandez-Barrera, M.Á.; Medina-Solís, C.E.; Márquez-Corona, M.D.L.; Vera-Guzmán, S.; Ascencio-Villagrán, A.; MinayaSánchez, M.; Casanova-Rosado, A.J. Edentulismo en adultos de Pachuca, México: Aspectos sociodemográficos y socioeconómicos. Rev. Clínica Periodoncia Implantol. Rehabil. Oral 2016, 9, 59-65. [CrossRef]

33. Menchaca-Díaz, R.; Bogarín-López, B.; Zamudio-Gómez, M.A.; Anzaldo-Campos, M.C. Periodontitis severa, edentulismo y neuropatía en pacientes con diabetes mellitus tipo 2. Gac. Médica México 2012, 148, 34-41. 